\title{
Juvenile Tillaux Fractures: A Comparison of Direct and Indirect Fixation
}

\author{
J. Eric Gordon*1,2,3, Perry L. Schoenecker ${ }^{1,2,3}$ and Sandra E. Klein ${ }^{1}$ \\ ${ }^{1}$ Washington University School of Medicine Department of Orthopaedic Surgery \\ ${ }^{2} \mathrm{St}$. Louis Children's Hospital \\ ${ }^{3}$ St. Louis Shriners Hospital
}

${ }^{\star}$ Corresponding author: J. Eric Gordon MD, 4S-60 St. Louis Children’s Hospital, 1 Children’s Place, St. Louis, Missouri, USA; Phone: 3144544194; Fax: 3144544562; Email: Gordone@wustl.edu

Received: June 27, 2019; Accepted: July 09, 2019; Published: July 11, 2019;

\begin{abstract}
Background: Two different screw configurations for the fixation of juvenile Tillaux fractures have been reported. One technique, direct fixation involves placement of one or two screws directly through the fragment, into the medial epiphysis or across the physis and into the metaphysis. The second technique involves placement of one or two screws through the medial epiphysis and into the fragment. The purpose of the study was to retrospectively study both techniques with regard to their effectiveness in maintaining an open anatomic reduction.

Methods: A review of all juvenile Tillaux fractures that had been operatively treated at our institution over a 5 year period was performed. A total of thirty-eight fractures were identified with twenty-three fractures (61\%) treated utilizing a direct fixation technique and fifteen fractures (39\%) treated utilizing an indirect fixation technique. All fractures were followed to union with a mean follow-up of twenty-one weeks.

Results: Thirty-four of the thirty-eight fractures were anatomically reduced on intraoperative radiographs with elimination of joint step-off on all radiographs and a residual one-millimeter fracture gap noted in four fractures. No fracture displaced between the time of internal fixation and healing. The mean healed fracture gap was $0 \mathrm{~mm}$ and the mean healed joint step-off was $0 \mathrm{~mm}$. Four of the fifteen fractures stabilized with indirect fixation required hardware removal. One of the twenty-three fractures stabilized using direct fixation required hardware removal.
\end{abstract}

Conclusion: Either direct or indirect fixation of juvenile Tillaux fractures is effective in maintaining an anatomic open reduction of the joint surface.

\section{Introduction}

The juvenile Tillaux fracture was first recognized by Paul Jules Tillaux [1] but was not extensively described until the report of Kleiger and Mankin [2]. The fracture occurs primarily in older adolescents in whom closure of the distal tibial physis has begun [3-7]. Early descriptions of the fracture reported successful treatment with closed reduction and casting [2,8,9]. However, reports of early degenerative changes in patients with displaced intraarticular distal tibia fractures have led to recommendations for open reduction and internal fixation in displaced intraarticular distal tibia fractures [10]. Some authors have advocated closed reduction with percutaneous fixation [11] or arthroscopic reduction [12,13] but open reduction is the standard of care [14-22]. The literature describes two different fixation techniques. The first involves placement of one or two pins or screws through the epiphyseal fragment and into the distal tibial metaphysis [18,20,21,23-25] (figure 1). The second technique involves placement of one or two screws through the medial malleolus and into the Tillaux fragment [17] (figure 2). Both techniques have been used at our institution. This study was performed to evaluate the effectiveness of each technique at maintaining the anatomic reduction obtained at the time of open reduction.

\section{Materials and Methods}

After obtaining institutional review board approval, a review of all distal tibial Tillaux fractures treated operatively at our institution between over a five year period was performed. Patients successfully treated with cast immobilization and without surgical intervention were excluded. Charts were reviewed for demographic information, operative details and postoperative complications and follow-up. Radiographs were reviewed for confirmation of the fracture pattern, the screw configuration used and intraoperative measurement of the displacement after fixation. Follow-up radiographs were reviewed to assess healing and measure displacement in both a transverse direction (fracture gap) and a vertical direction (joint step off).

A total of forty-five patients with forty-five fractures were identified. Seven patients had radiographs that could not be located or inadequate follow-up for inclusion in the study. A total of thirtyeight patients with thirty-eight fractures were identified that were followed to union. A total of sixteen males and twenty-two females were included. The mean age of the patients was thirteen years and eight months (range eleven years and one month to sixteen years and two months). The right ankle was involved in twenty-two fractures 
(58\%) and the left in sixteen (42\%). A total of twenty-three fractures (61\%) were stabilized using direct fixation while fifteen fractures (39\%) underwent indirect fixation. All patients were followed to fracture union, which occurred in all fractures within six weeks after the injury. The mean follow up was twenty-one weeks (range six to 124 weeks)

\section{Surgical Technique}

After the patient had been placed in the supine position with a bump under the ipsilateral hip, the involved extremity was prepared and draped free. Under tourniquet, in all patients, an anterior longitudinal incision was made over the ankle and dissection was performed down to the level of the anterior tibial tendon. Dissecting either medial to the anterior tibial tendon or between the anterior tibial tendon and the extensor hallicus longus tendon an arthrotomy was then performed. The Tillaux fragment was then identified and distracted by inserting a freer elevator into the fracture site. Hematoma was then curetted from the fracture site and the ankle joint thoroughly irrigated. The articular surface was then reduced under direct vision using the elevator and held reduced using a large bone reduction

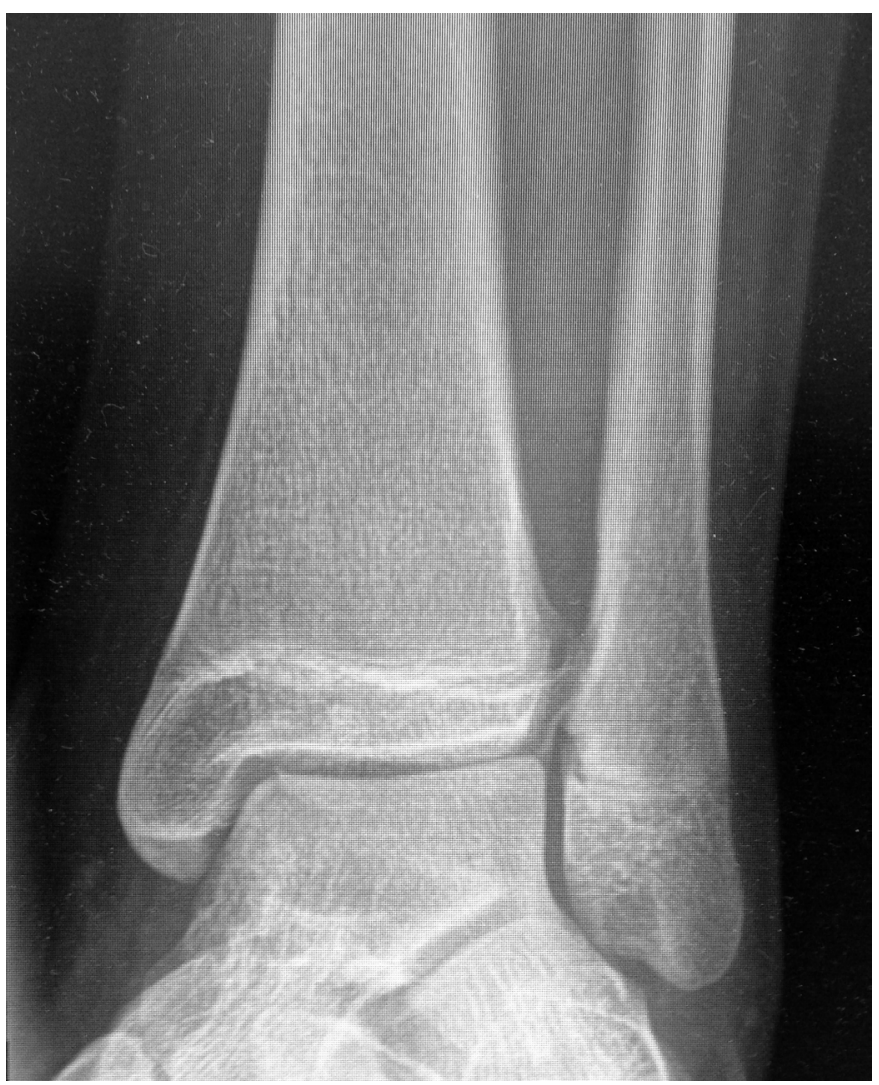

Figure 1a. Anteroposterior radiograph of the left ankle in a $13+0$ year old female after a twisting injury sustained after stepping into a hole showing a displaced Tillaux fracture. clamp. One of two fixation configurations was then used after open reduction at the surgeon's discretion. The first technique, designated direct fixation, involved the placement of one or two cannulated $4.0 \mathrm{~mm}$, partially threaded, interfragmentary screws (Smith-NephewRichards, Memphis, Tennessee, USA) angled proximally, medially and posteriorly through the Tillaux fragment and into either the distal tibial epiphysis or across the physis and into the metaphysis (Fig. 1a-f). The second technique, designated indirect fixation ${ }^{17}$, involved making a small $(3 \mathrm{~mm})$ incision over the medial aspect of the epiphysis and placement of one or two cannulated interfragmentary screws through the medial epiphysis between the physis and the joint surface using image intensification (Fig. 2a-e). Closure of the incisions was carried out after confirming anatomic reduction both visually by inspecting the joint surface and by using image intensification. Regardless of the screw configuration utilized, the ankle was immobilized in a short leg cast or orthotic walker boot and the patient was requested to be non-weight bearing for six weeks. Hardware removal was not routinely performed after fracture healing but was performed if the patent experienced significant discomfort with activity over the area of screws.

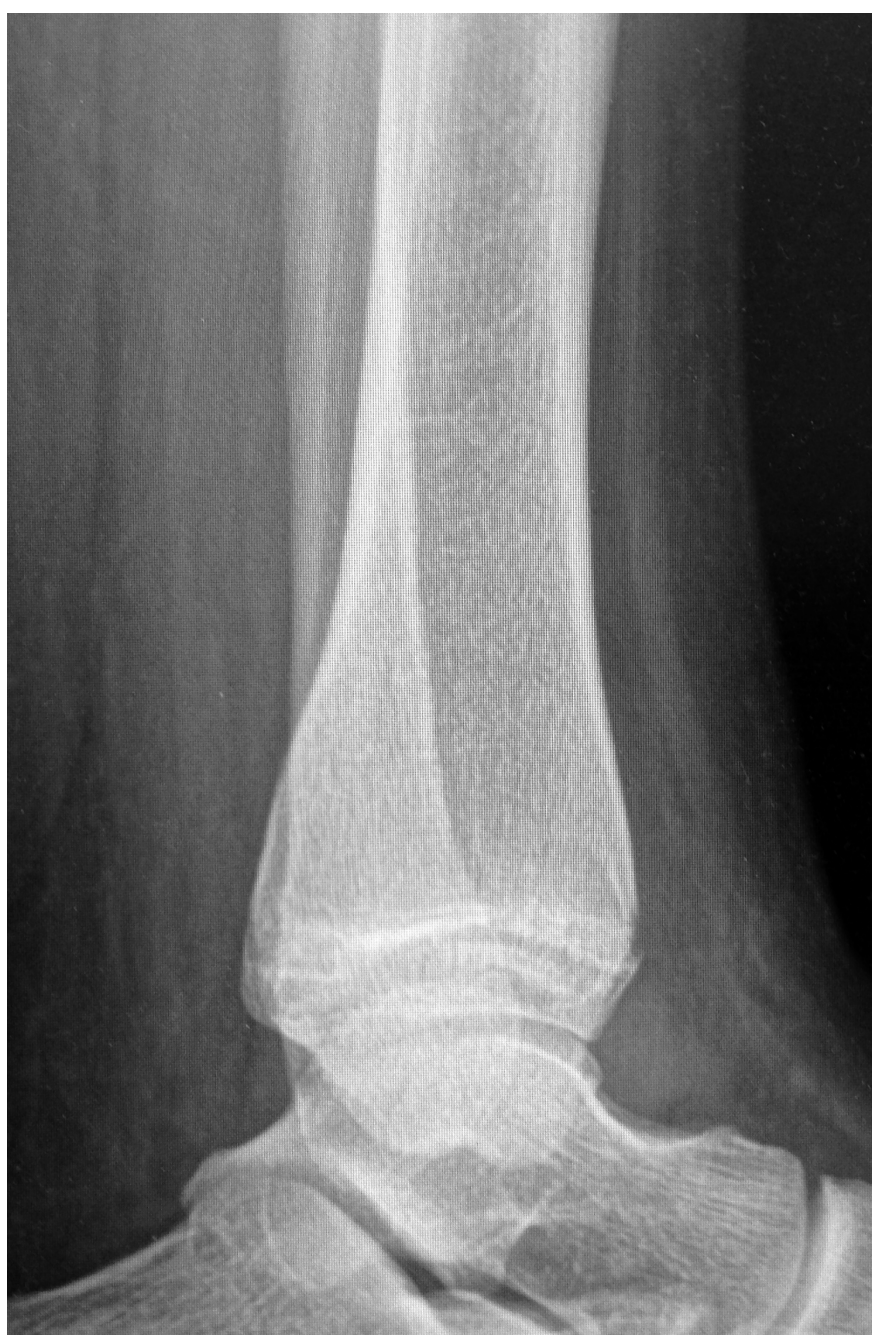

Figure 1b. Lateral radiograph of the left ankle in the same patient. 


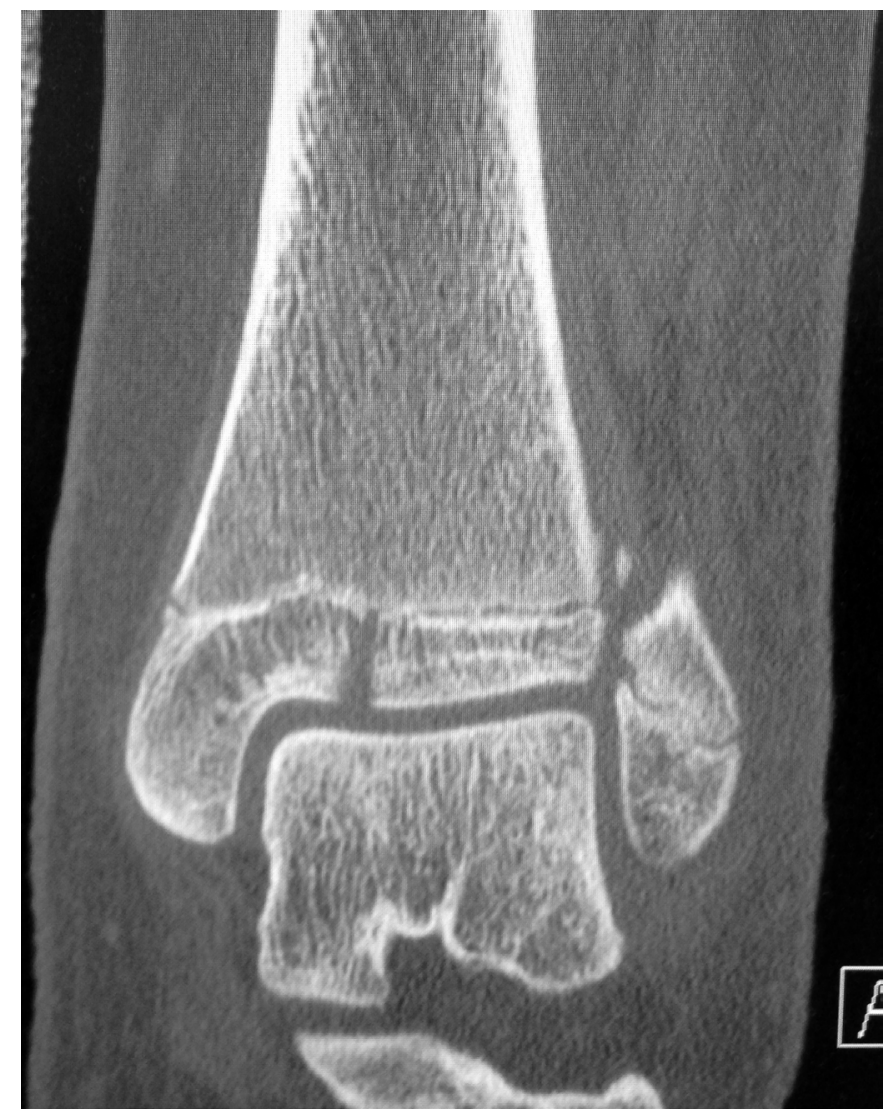

Figure 1c. Coronal reconstruction of computed tomography of the distal tibia following closed reduction showing significant gapping of the Tillaux fragment.

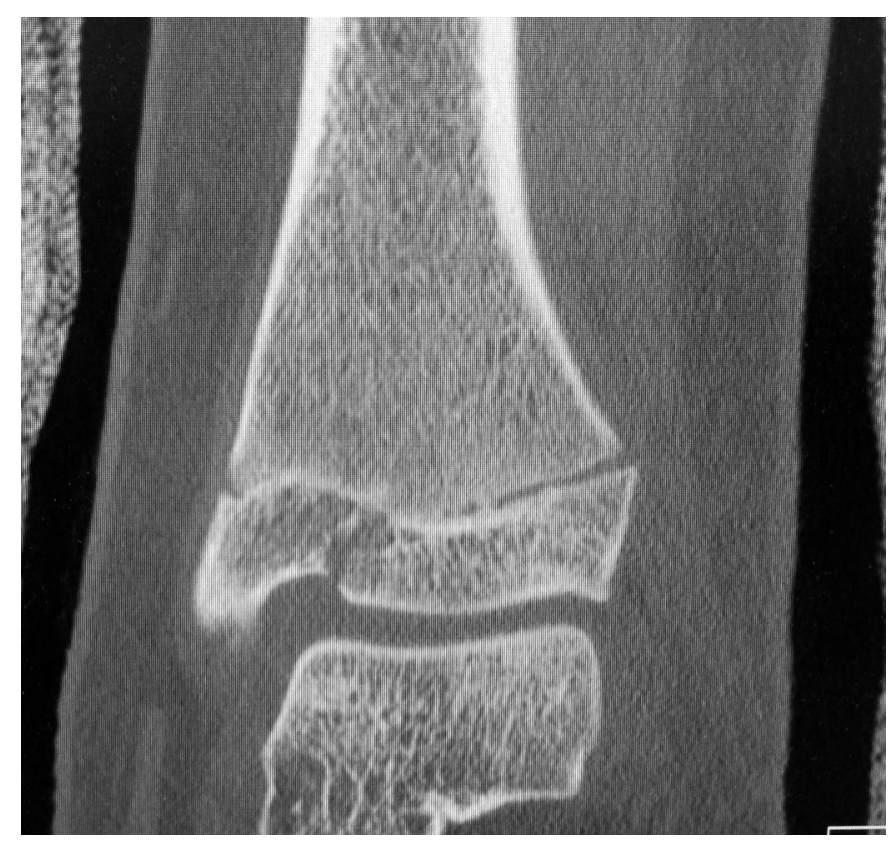

Figure 1d. Coronal reconstruction of computed tomography of the distal tibia in the mid tibia following closed reduction showing mild displacement of the Tillaux fragment.

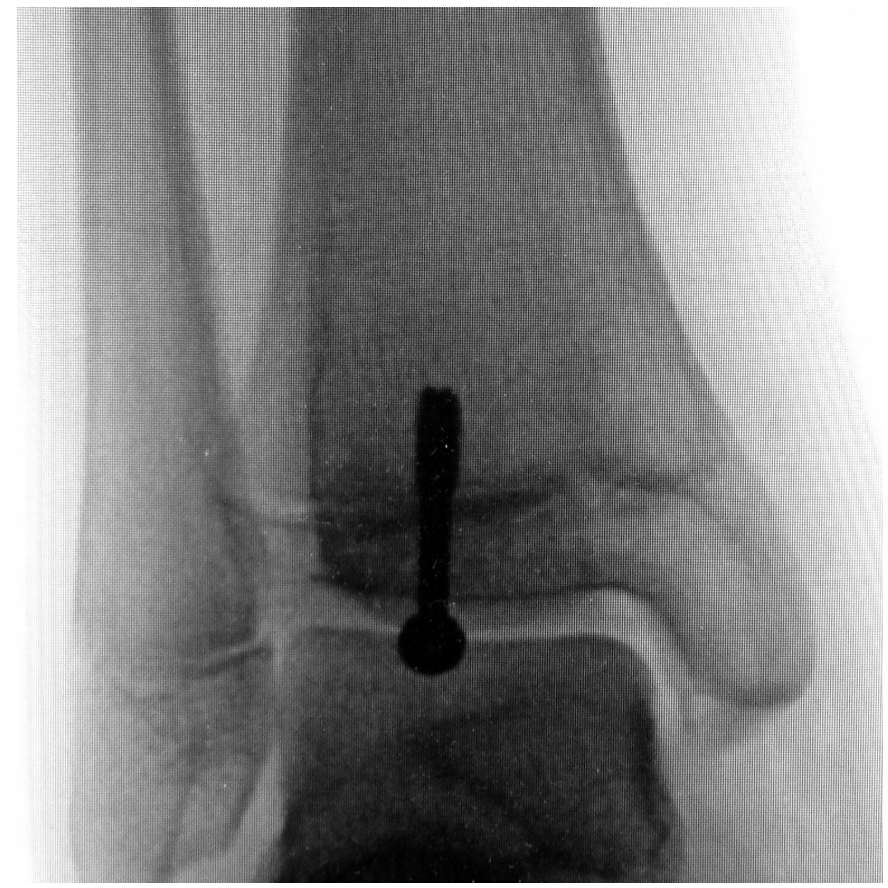

Figure 1e. Anteroposterior intraoperative image of the ankle in the same patient obtained using an image intensifier intraoperatively after open anatomic reduction and internal fixation using direct fixation with one screw

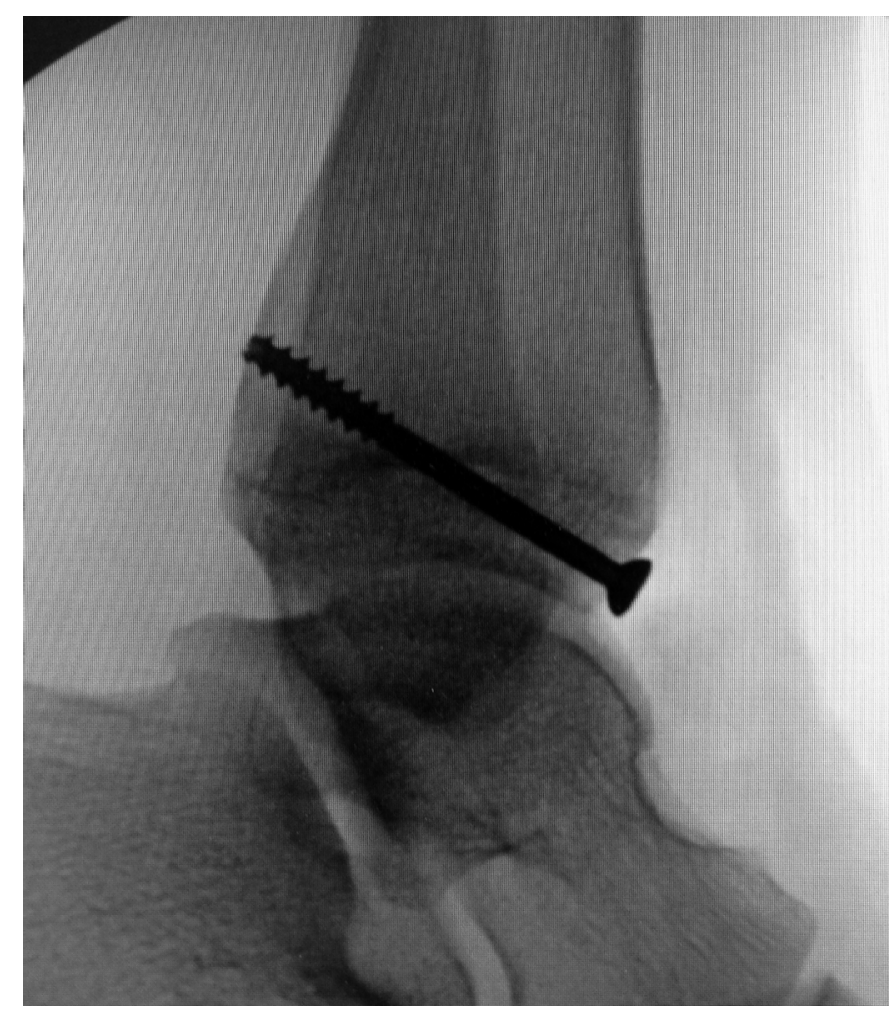

Figure 1f. Lateral image of the ankle in the same patient. 


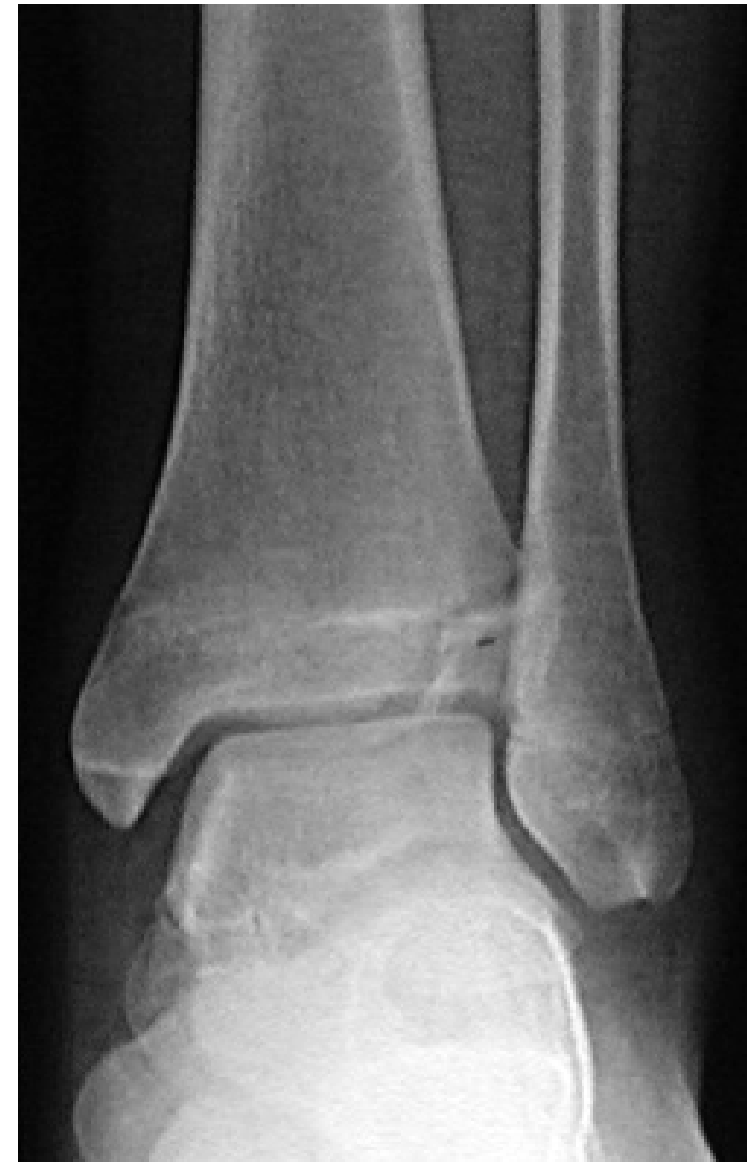

Figure 2a. Anteroposterior radiograph of the left ankle in a $12+6$ year old female after an injury sustained while playing soccer. A displaced Tillaux fracture is present

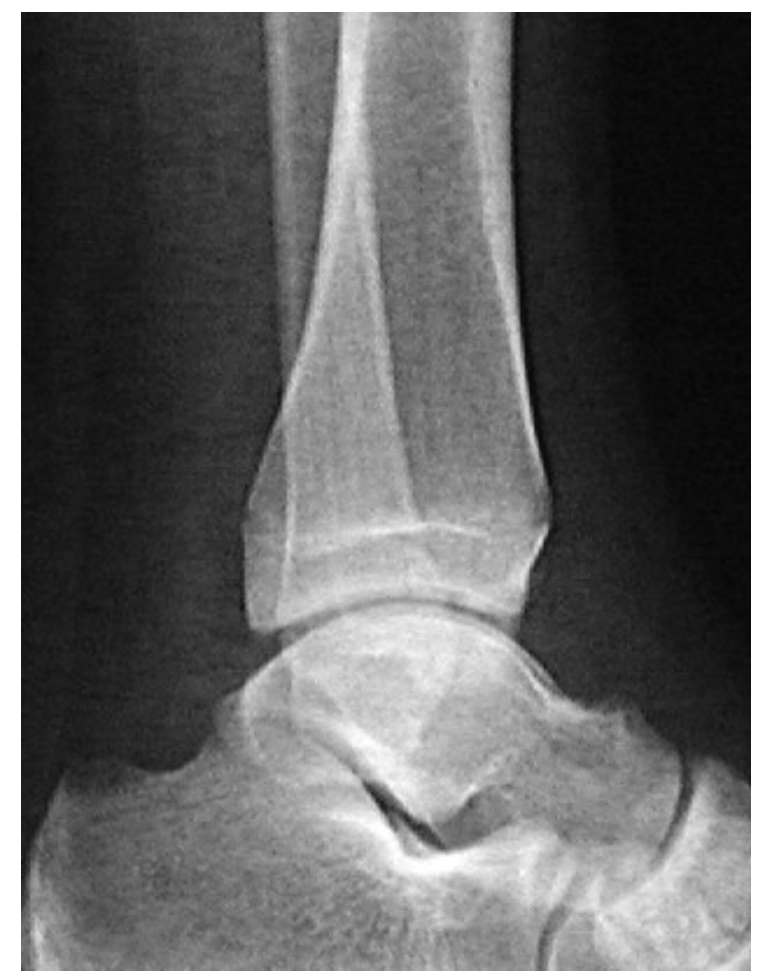

Figure 2b. Lateral radiograph of the left ankle in the same patient.

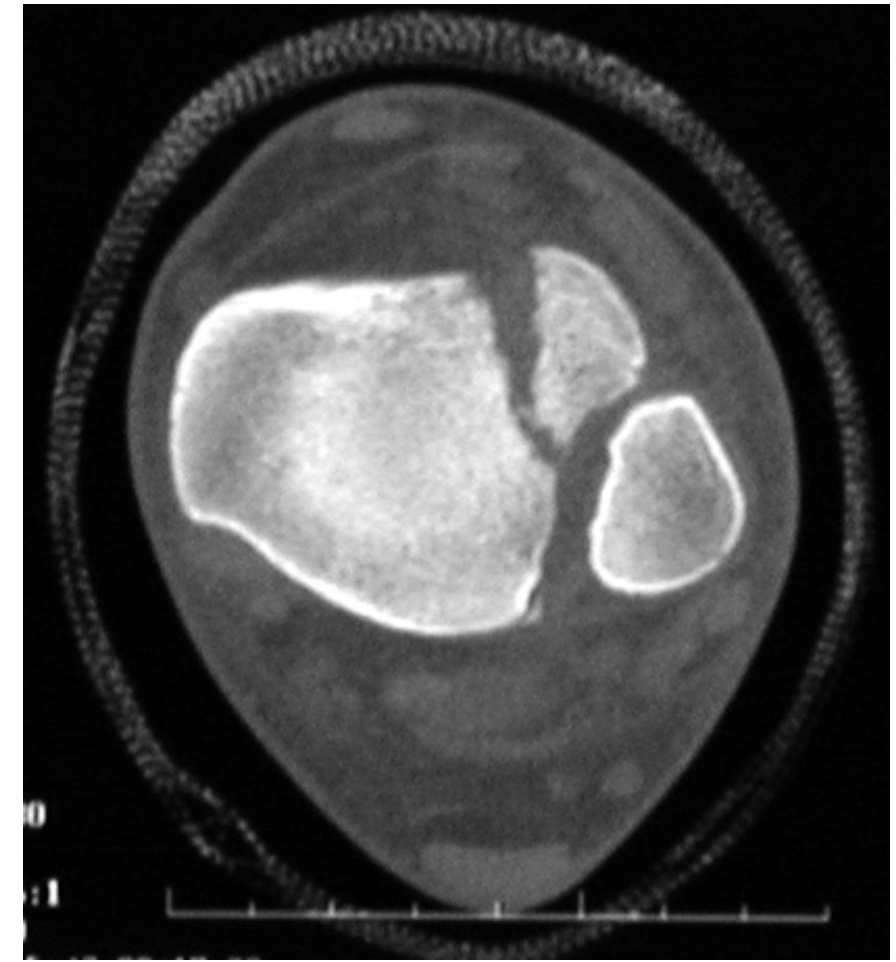

Figure 2c. Computed axial tomographic image of the left distal tibia showing displacement of the Tillaux fragment.

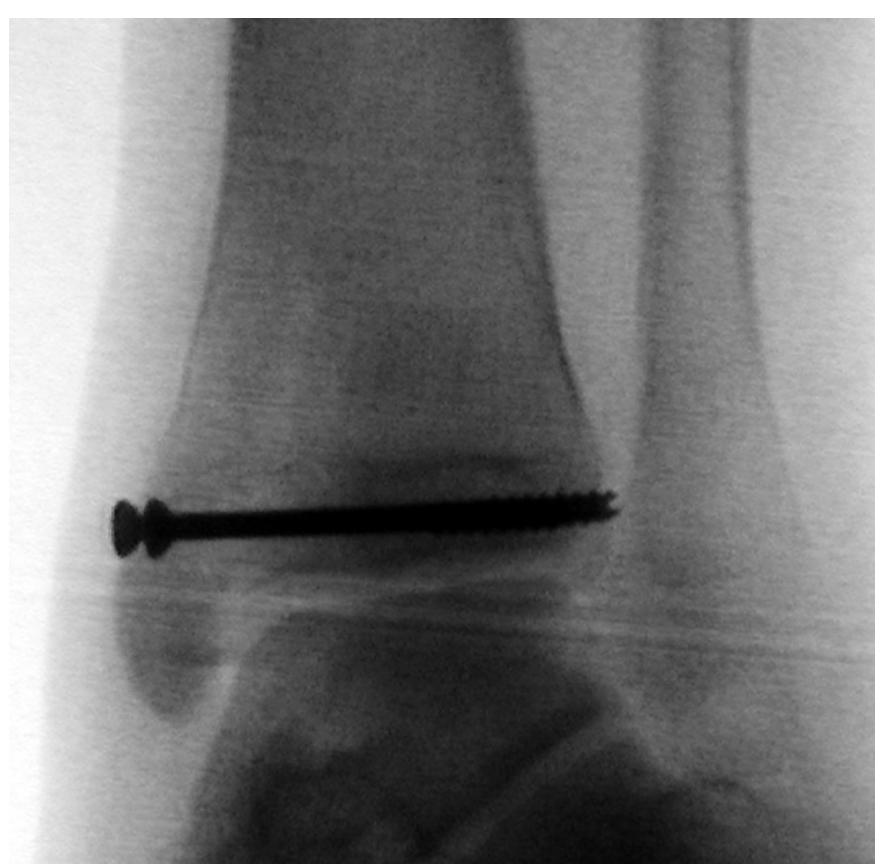

Figure 2d. Intraoperative anteroposterior image of the ankle in the same patient obtained using an image intensifier intraoperatively after open anatomic reduction and internal fixation using indirect fixation with two screws. 


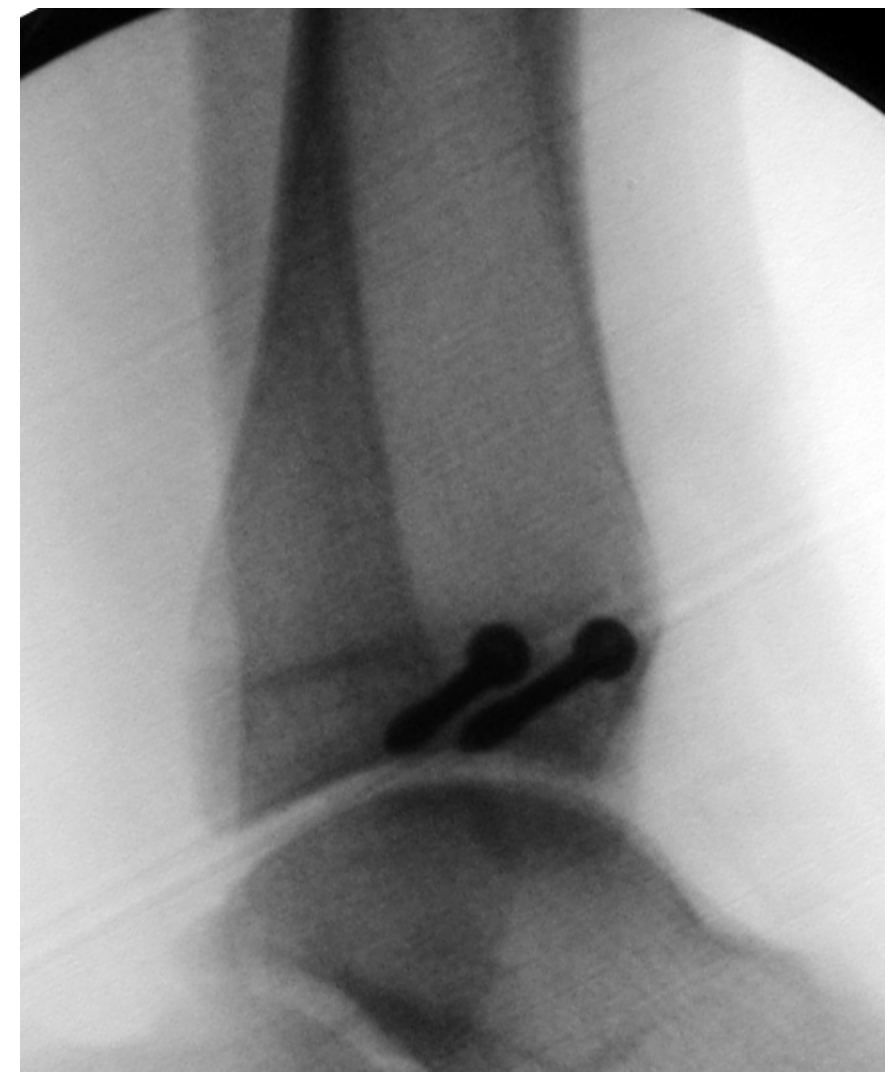

Figure 2e. Intraoperative lateral image of the ankle in the same patient obtained using an image intensifier intraoperatively after open anatomic reduction and internal fixation using indirect fixation with two screws.

\section{Results}

Anatomic reduction was obtained in thirty-four of the thirty-eight fractures at the time of operative fixation. Joint step off was eliminated in all patients. Three of the twenty-three fractures treated by direct fixation (13\%) and one of the fifteen fractures treated by indirect fixation (7\%) were noted to have a residual one-millimeter fracture gap intraoperatively that was felt to be acceptable. Measurements at the time of bony union revealed that no fracture had displaced joint step off (mean $0 \mathrm{~mm}$ ). At the time of union, no patient had a measurable fracture gap (mean $0 \mathrm{~mm}$ ). One of the twenty-three patients who had direct fixation $(4 \%)$ requested hardware removal. Four of the fifteen patients who had indirect fixation (29\%) requested hardware removal. No intraoperative or postoperative complications occurred although transient tingling in the distribution of the superficial peroneal nerve was noted postoperatively in a few patients. This had resolved by the time of final follow-up in all patients. No patient developed other neurovascular complications, wound problems or infection. Hardware removal was uncomplicated in all patients who requested removal of the screws.

\section{Discussion}

Juvenile Tillaux fractures are uncommon and most reports consist of small series or case reports with the largest series in the literature representing 10 patients [26,27] Here we report the operative experience at our institution over an extended period of time with this uncommon fracture. Our routine during this time has been to perform antero-posterior, lateral, and mortise radiographs as the initial radiographic evaluation. Fractures that were displaced were splinted and operative treatment recommended. Fractures that were not clearly displaced were placed into long leg casts with the knee bent $45-90^{\circ}$. After cast placement, computed tomography with coronal and sagittal reconstruction was performed to evaluate the joint surface $[19,28-33]$. Displacement with fracture gap or joint step-off of more than $1 \mathrm{~mm}$ was considered to be significant and operative treatment recommended. Operative treatment in each instance involved open reduction with internal fixation using $4.0 \mathrm{~mm}$ cannulated screws. Closed reduction of these fractures, if attempted was performed prior to definitive imaging and in our experience rarely achieved the anatomic reduction of the joint surface that we believe is essential to good long-term results.

The advantage of direct fixation is that it is technically slightly easier, not requiring joint space visualization and image intensification needed for indirect fixation. In addition, direct fixation does not require additional incisions to be made in the area of the medial malleolus. Crossing the physis typically involves little risk of late growth problems because these fractures typically occur after closure of the posterior and medial aspects of the distal tibial physis ${ }^{2,7}$. Indirect fixation has the advantage of requiring a slightly smaller anterior incision because drilling and screw placement is not performed through this incision. Indirect fixation also has the advantage of simplified screw removal in the event of painful hardware. Hardware removal was more frequently requested in the patients who had been stabilized using indirect fixation, possibly due to prominence of the screws at the medial malleolus causing problems with shoe wear. Either technique seems to be effective in maintaining an anatomic reduction that has been achieved by open reduction.

In conclusion, both direct and indirect fixation of juvenile Tillaux fractures are effective in maintaining an anatomic reduction of the fracture when the limb is immobilized in a short leg, below knee cast or orthotic walker boot when the patient is kept non-weight bearing.

\section{Acknowledgement}

Study conducted at Washington University School of Medicine, St. Louis Shriners Hospital for Children, and St. Louis Children's Hospital, St. Louis, Missouri, USA.

\section{References}

1. Rang M (1983) Children's Fractures. (2 $2^{\text {nd }}$ edn). Philadelphia and Toronto: J.B. Lippincott Company 1983.

2. Kleiger B, Mankin HJ (1964) Fracture of the lateral portion of the distal tibial epiphysis. J Bone Joint Surg [Am] 46: 25-32.

3. Protas JM, Kornblatt BA (1981) Fractures of the lateral margin of the distal tibia. The Tillaux fracture. Radiology 138: 55-7.

4. Letts RM (1982) The hidden adolescent ankle fracture. J Pediatr Orthop 2: 161-4.

5. Love SM, Ganey T, Ogden JA (1990) Postnatal epiphyseal development: the distal tibia and fibula. J Pediatr Orthop. 10: 298-305.

6. Ogden JA, McCarthy SM (1983) Radiology of postnatal skeletal development. VIII. Distal tibia and fibula. Skeletal Radiol 10: 209-20.

7. Spinella AJ, Turco VJ (1988) Avulsion fracture of the distal tibial epiphysis in skeletally immature athletes (juvenile Tillaux fracture). Orthop Rev 17: 1245-9.

8. Kleiger B (1956) The mechanism of ankle injuries. J Bone Joint Surg [Am] 38: 59-70. 
9. Spiegel PG, Cooperman DR, Laros GS (1978) Epiphyseal fractures of the distal ends of the tibia and fibula. J Bone Joint Surg [Am] 60: 1046-50.

10. Ertl JP, Barrack RL, Alexander AH, VanBuecken K (1988) Triplane fracture of the distal tibial epiphysis. J Bone Joint Surg [Am] 70: 967-76.

11. Schlesinger I, Wedge JH (1993) Percutaneous reduction and fixation of displaced juvenile Tillaux fractures: a new surgical technique. J Pediatr Orthop 13: 389-91.

12. Leetun DT, Ireland ML (2002) Arthroscopically assisted reduction and fixation of a juvenile Tillaux fracture. Arthroscopy 18: 427-9.

13. Ogawa T, Shimizu S (2017) Arthroscopically assisted surgical fixation of a juvenile Tillaux fracture and implant removal: A case report. J Clin Orthop Trauma 8: 32-7.

14. Dailiana ZH, Malizos KN, Zacharis K, Mavrodontidis AN, Shiamishis GA, et al (1999) Distal tibial epiphyseal fractures in adolescents. Am J Orthop 28: 309-12.

15. de Sanctis N, Della Corte S, Pempinello C (2000) Distal tibial and fibular epiphyseal fractures in children: prognostic criteria and long-term results in 158 patients. $J$ Pediatr Orthop B 9: 40-4.

16. Koury SI, Stone CK, Harrell G, La Charite DD (1999) Recognition and management of Tillaux fractures in adolescents. Pediatr Emerg Care 15: 37-9.

17. Lintecum N, Blasier RD (1996) Direct reduction with indirect fixation of distal tibial physeal fractures: a report of a technique. J Pediatr Orthop 16: 107-112.

18. Kling TF Jr (1990) Operative treatment of ankle fractures in children. Orthop Clin North Am. 21: 381-92.

19. von Laer L (1985) Classification, diagnosis, and treatment of transitional fractures of the distal part of the tibia. J Bone Joint Surg [Am]. 67: 687-98.

20. Kling TF, Jr., Bright RW, Hensinger RN (1984) Distal tibial physeal fractures in children that may require open reduction. $J$ Bone Joint Surg [Am] 66: 647-57.

21. Dias LS, Giegerich CR (1983) Fractures of the distal tibial epiphysis in adolescence. $J$ Bone Joint Surg [Am] 65: 438-444.
22. Britton PD (1988) Adolescent-type Tillaux fracture of the ankle: two case reports. Arch Emerg Med 5: 180-3.

23. Dingeman RD, Shaver GB (1978) Operative treatment of displaced Salter-Harris III distal tibial fractures. Clin Orthop 135: 101-103.

24. Salter RB (1974) Injuries of the ankle in children. Orthop Clin North Am 1974;5: $147-152$.

25. Dias LS, Tachdjian MO (1978) Physeal injuries of the ankle in children. Clin Orthop 136: 230-3.

26. Tiefenboeck TM, Binder H, Joestl J, et al. (2017) Displaced juvenile Tillaux fractures : Surgical treatment and outcome. Wien Klin Wochenschr 129: 169-75.

27. Kaya A, Altay T, Ozturk H, Karapinar L (2007) Open reduction and internal fixation in displaced juvenile Tillaux fractures. Injury 38: 201-5.

28. Yao J, Huurman WW (1986) Tomography in a juvenile Tillaux fracture. J Pediatr Orthop 6: 349-51.

29. Felman AH (1989) Tillaux fractures of the tibia (in adolescents). Pediatr Radiol 20: 87-9.

30. Horn BD, Crisci K, Krug M, Pizzutillo PD, MacEwen GD (2001) Radiologic evaluation of juvenile Tillaux fractures of the distal tibia. J Pediatr Orthop 21: $162-4$.

31. O'Connor DK, Mulligan ME (1998) Extra-articular triplane fracture of the distal tibia: a case report. Pediatr Radiol. 28: 332-3.

32. Steinlauf SD, Stricker SJ, Hulen CA (1998) Juvenile Tillaux fracture simulating syndesmosis separation: a case report. Foot Ankle Int 19(5): 332-5.

33. Karrholm J (1997) The triplane fracture: four years of follow-up of 21 cases and review of the literature. J Pediatr Orthop B 6: 91-102.

Citation:

Gordon JE, Schoenecker PL, Klein SE (2019) Juvenile Tillaux Fractures: A Comparison of Direct and Indirect Fixation. Integr J Orthop Traumatol Volume 2 (3): 1-6. 